\title{
ENVIRONMENTAL POLICIES AND NATURAL RESOURCE MANAGEMENT IN SOUTHEAST ASIA
}

\section{ABSTRACT}

Recently, environmental issues have become a priority in the agenda of ASEAN countries due to the serious impacts of environmental degradation. Similar to other countries, ASEAN countries have their own strengths and weaknesses in environmental protection, which depend on their policies and law enforcement. This paper consists of three parts. The first part introduces the environmental problems of the region. The second part discusses environmental approaches, namely pricing policy, green tax and community involvement as well as assistance from developed countries to realise the goals of sustainable development. The last part analyzes the shortcomings of these policies and proposes a line of environmental problems and reasoning enhancing the overall quality of life and growth.

KEY WORDS: Environmental Problems, Resource Management, Policy Issues

\section{INTRODUCTION}

Although sustainable development has been a priority in the agenda of many governments in Southeast Asia (SEA), current levels of resources consumption and wastes production of have not been reduced. In the context of multi-dimension constraints, such as lack of political will, lack of cooperation among involved parties, lack of funds, weak law enforcement and inconsistent regulations as well as the current economic crisis, people in these countries have to adapt to dramatic changes and unconsciously destroy the environment at a rapid pace. Thus, ASEAN countries share the following common environmental problems.

\subsection{Land / soil deterioration and deforestation}

Southeast Asia has limited land and soil resources when compared to its huge 400-million population. Together with population pressure, land resources are deteriorating due to uncontrolled soil erosion, forest loss and unplanned cultivation. Land and soil along the rivers are eroded and carried away by floods or high tide.

With regard to deforestation, forest areas are shrinking rapidly due to illegal logging and unplanned cultivation. Forest loss contributes to climate changes and natural disasters (floods, draught), while it causes famine of people in the 
region. For example, the forest areas in Cambodia have decreased from about $74 \%$ in the early 1970's to 30-35\% in 1995 (Global Witness, 1995). Also in Sad Dai community in Cambodia, forest loss caused serious famine. Almost all villagers were ill nourished and suffered from heart palpitations, difficulty in breathing and coughing as well as diarrhea (Global Witness, 1995).

\subsection{Water pollution}

Together with climate conditions (no rain or little rain) and limited ground or surface water sources, industries and households are the main culprits which cause water pollution and water shortage. Water is contaminated with chemicals, suspended solids, and germs from factories which do not have adequate wastes control and treatment equipment. For instance, in Indonesia, solid waste from pulp mills and steel-making factories, which is not treated before discharge, pollutes local fisheries and irrigated rice fields (Pargal and Wheeler, 1995).

Sewage often flows through open street drains and then runs into the river with little or no treatment. Transportation is also one of the culprits which contribute to water pollution. Liquid waste from boat vessels causes water contamination.

In the region, about 25 million people die every year because of contaminated drinking water. Lack of sanitary facilities and dirty water cause $80 \%$ of all diseases affecting the developing countries (Singapore Ministry of Environment, 10/1997). Besides, the shortage of capital and technology makes it difficult to have an access to safe drinking water. Only $69 \%$ of the urban population in Vietnam can get clean water while only about $50 \%$ can have an access to safe drinking water (Project VIE/89/021). In addition, the disturbed catchments by illegal or unplanned logging and the construction of mega projects as well as the high level of ammonia content in raw water forced the water-supply station in Cheras (Malaysia) to shut down. These reasons and the high dependence on the surface water caused the water crisis in Malaysia in March and April 1998 (Ithnin, 1998).

\subsection{Air pollution, global warming and ozone depletion}

Droughts and forest fires caused haze in Southeast Asia in 1997 - 1998. Forest fires destroyed hundreds of hectares of forest in Indonesia, Malaysia and Brunei. Thick haze caused eye irritations, headache, respiratory problems while schools in Brunei had to close when the pollutant standard index (PSI) reached 300 (Odihi, 1998). In Singapore, the government had to prepare masks to be used in case of hazardous emergency.

Table 1: Main Pollutants, Discharged by Major Industries in Thailand

\begin{tabular}{|ll|}
\hline Industries & Main Pollutants \\
\hline Grain processing \& Incinerators & dust and combustion pollutants \\
Canning, Edible oil extraction & combustion pollutants, odors \\
Food additives/Bakeries & combustion pollutants, odors \\
Fishmeal and bonemeal & dust, odor, combustion pollutants \\
Textiles & combustion pollutants \\
Pulp and paper & combustion pollutants, odors \\
Agro-industry & dust, combustion pollutants, odors \\
Plastics and Chemicals & combustion products, odors \\
Oil refineries & dust, combustion products, odors \\
Ceramics \& Glass & dust, combustion products \\
Metal & dust, smelting products \\
Mineral & combustion pollutants, dust \\
Machinery production & odors, combustion pollutants \\
Power generation & combustion pollutants, dust \\
Gas Separation & odors, combustion pollutants \\
\hline
\end{tabular}

Source: format by the author and content from "Industrial Air Emission Database for Thailand 1994" (http://www.pcd.go.th/ AirPollution94THAILAND.htm). 
Moreover, other gas emissions make air pollution more serious. In Vietnam, Nguyen (1996) pointed out that "... compared with other cities, such as Beijing, Tokyo, Bangkok and Manila, ....the levels of $\mathrm{CO}$ and $\mathrm{NO}_{2}$ are approaching the levels of these cities. In the case of particulate emissions, their peak values at some heavy traffic sites in Ho Chi Minh City are very high and exceed those of Bangkok and Manila. .... The concentration of CO measured on $25 / 04 / 1996$ was $62.65 \mathrm{mg} / \mathrm{m}^{3}, 1.5$ times above the standard. Similarly, the $\mathrm{NO}_{2}$ concentration measured on 23/04/1996 exceeded the standard by 1.5 times. The average noise level is between 76 to $86 \mathrm{~dB}$ with a peak of $98 \mathrm{~dB}$, while the standard for residential areas is $60 \mathrm{~dB}$ " (Nguyen 1996). In Malaysia, the number of pollution complaints were 4,254 in 1997, greater by $34 \%$ when compared to 1996 (The Malaysia Environmental Quality Report 1997). According to the report, "the bulk of complaints (79\%) pertained to air pollution, principally black smoke emission from diesel motor vehicles, and complaints received during the haze episode from July to September 1997 also increased."

Table 1 summarizes main pollutants discharged by major industries in Thailand.

\subsection{Urban and Industrial wastes}

Solid waste disposal has become a major problem in the urban rural areas. Garbage is littered on the streets or thrown into the river. Landfills are untreated dumpsites that leak into both surface and groundwater sources. In Vietnam, only half of the domestic and industrial waste is col- lected properly, while the rest is scattered arbitrarily into the lakes, the rivers and on the dumping ground. In Malaysia, "the number of notifications on waste generation from scheduled waste generators increased by 28\%, from 2252 in 1996 to 3103 in 1997". Among the "5290 enforcement visits relating to industrial effluent discharges of non-prescribed premises carried out", 888 (16.82\%) did not comply with the Environmental Quality (Sewage and Industrial Effluents) Regulations, 1979 (The Malaysia Environmental Quality Report, 1997).

\subsection{Population pressure}

The premises of economics "people's wishes are unlimited while resources are limited" can totally be applied in this case. Increasing population pressures cause significant environmental degradation. When the population increases, the need for land and other resources also increases. Thus, more forests are converted into agricultural land and natural resources are over-exploited. In addition, downgraded social and technical infrastructure cannot meet the requirements of increased population. As a result, sanitary problems and lack of basic goods affect population's standard of living.

Table 2 presents the population and population growth rate in Southeast Asia countries. Since population pressure in conjunction to the socioeconomic conditions is considered one of the main reasons for environmental degradation, the table will help readers have a general view of the rapid population growth rate in these countries,

Table 2: Population and the Population Growth Rate in Southeast Asia (6/1998) $6 / 1998$

6/1999

\begin{tabular}{|l|c|c|c|c|}
\hline Country & Population & Growth Rate & Population & Growth rate \\
\hline Brunei & 315,292 & $2.44 \%$ & 322,982 & $2.38 \%$ \\
Cambodia & $11,339,562$ & $2.51 \%$ & $11,626,520$ & $2.49 \%$ \\
Indonesia & $212,941,810$ & $1.49 \%$ & $216,108,345$ & $1.46 \%$ \\
Laos & $5,260,842$ & $2.76 \%$ & $5,407,453$ & $2.74 \%$ \\
Malaysia & $20,932,901$ & $2.11 \%$ & $21,376,066$ & $2.08 \%$ \\
Myanmar & $47,305,319$ & $1.65 \%$ & $48,081,302$ & $1.61 \%$ \\
Philippines & $77,725,862$ & $2.09 \%$ & $79,345,812$ & $2.04 \%$ \\
Singapore & $3,490,356$ & $1.20 \%$ & $3,531,600$ & $1.15 \%$ \\
Thailand & $60,037,366$ & $0.97 \%$ & $60,609,046$ & $0.93 \%$ \\
Vietnam & $76,236,259$ & $1.43 \%$ & $77,311,210$ & $1.37 \%$ \\
\hline
\end{tabular}

Source: CIA World Factbook 1998 and 1999, http://www.worldrover.com/ vitalmain.htm,

and http://www.odci.gov/cia/publications/factbook/cb.html 
especially in Laos $(2.74 \%)$ and Cambodia $(2.49 \%)$ in 1999.

\section{RESOURCE MANAGEMENT AND ENVIRONMENTAL POLICIES}

To address the above-mentioned environmental problems, the SEA governments constructively issue environmental policies. Among these policies, some issues should be highlighted since they present a new point of view towards environmental protection.

\subsection{Pricing policy or fee of using environment}

Nowadays, "free goods" as fresh air or water in the rivers/at sea are no longer as available as they were before. The cost of overusing these resources is paid by the increased health and hazardous problems discussed previously. Thus, introducing prices of environment can prevent people from abusing or wasting natural resources. If people do not have to pay for using environmental resources, they will not change their behavior towards nature and keep on being free riders. Especially in agriculture, policies on "commodity prices, incentives for farmers and input subsidies have great impact on reducing erosion, pollution and abuse of scare resources" (Goh, 1997). For example, the Indonesia government encouraged farmers "to do the gardening, to grow fruit, soya beans, mixed cropping and livestock that are relatively environmentally benign" (Goh, 1997). Vietnamese government subsidized farmers to make use of land by growing multi-season crops and to use fertilizer properly. The farmers are also asked to utilize their land by growing vegetables in between the main crops as well as growing some kinds of plantation which can enrich the soil, such as soya bean, sweet potatoes and different types of beans.

However, the price of environment is very difficult to set since the economic price only reflects the present value, not the future consequences. Besides, limited resources (limited land, slow reproductive soil), fund mis-management and over-fertilizing may generate counter-productive results. This means that if farmers use too much fertilizer, then land may become dried or less fertile. In most of developing countries, the difficulty to have an access to credit and technology makes the preservation and rehabilitation of soil and land being a challenging task. Thus, a proper policy to help quality and productivity increase, such as price control and fair competition, may generate incentives for farmers to increase their income. At the same time, technical assistance and training should be highlighted as Goh is suggesting: "the governments should reallocate input subsidies and output to make sure that efficiency and equity can be achieved. In addition, access to credits and increase of fund for developing new model of farms as well as for improving physical infrastructure to reduce the cost of production, may help to tackle the problem of resource constraints" (Goh, 1997).

\subsection{Management of resources by governmental regulation}

As in the case of "market failure", governments have intervened in the resource management. Market failure refers to public goods, which users prefer to consume but do not want to pay, such as street-lights or radio broadcasting. "Public goods" is usually synonymous with "free-ridership" because nobody wants to pay a fee for using the environment. It also refers to externalities and distorted information. Here, I would like to emphasize on negative externalities (noise, smoke, air pollution, water pollution, etc.), which yield adverse effects on ecosystem and human beings. Therefore, governments should keep the main role in making policies to preserve and develop natural resources. Resources should be exploited properly because some resources will be useless if they are maintained at the status quo. With regard to this aspect, SEA governments show their commitment by enacting ownership rights, such as property rights, land ownership, user-right, intellectual rights and controll over natural and human resources (Goh, 1997). Naturally, people will preserve and renovate what belongs to them. Thus, rights of ownership may be a good solution to solve the problem of "collective ownership" and "moral hazard". However, the enforcement of law is still in question. What happens if someone violates the regulation? Which mechanism should be employed to tackle dispute in relation to ownership issues, the court or the community?

Recently, ASEAN governments have made special efforts to conserve nature. For example, Singapore Green plan, which was started since 1992, aims at creating a Model Green City in the 
region. To achieve sustainable development, Singapore promotes the use of clean technology and enhances the awareness of the public in protecting domestic and regional environment. Singapore tries to keep the amount of carbon dioxide below the allowed limit given by OECD. Strategic measures are practiced to save energy consumed and to control waste and emissions (Singapore Ministry Environment, exhibition in 10/1997). In Vietnam, the Prime Minister enacted decision No. 845/TTg (22/12/1995) about "Action plan to protect Vietnam's biological diversity" and the instruction of No. 359/TTg on (29/5/1996) about "Urgent measures to protect and develop wild animals". These regulations generated positive results, such as the restoration of natural living environment in Thua Thien province. Precious species of animals, namely Azure elephants, "Sao LA" (a kind of deer), tigers and panthers have been seen again. It means they can still survive despite the harsh living conditions ( $D r$. Do Nam, Vietnam Southeast Asia Today, 4/1997).

\subsection{Green tax and clean technologies}

Green tax and clean technologies are proper measures to meet the goals of environmental protection. Effluent tax may make factories to add pollution controls or change production process or redesign products, which can generate less waste. Green tax levied in fuel price may decrease the number of car-owners and the amount of fuel used (Lester Brown, Christopher Flami and Sandra Postel, 1996). Nevertheless, this method can only work when public transportation is efficient as in Singapore. Green tax aims at encouraging users, mainly companies, factories and households to choose proper technology in production and to use materials which can be recycled. For instance, Singaporean people have to obtain a Certificate of Entitlement (COE), which costs more than $S \$ 30,000$ per car per 10 years, in order to have the right to own a car. This scheme helps Singapore government limit the number of car-owners, which can tackle the problem of traffic jam and air pollution.

Besides, obsolete technology and secondhand vehicles and machines are discouraged in these countries. Also, the import of ozone depleting substances, such as petrol with lead, should be reduced at a minimum level in accordance with international standards. Governments invest more in Research and Development (R \& D), which concentrates on the innovation of new environmental technologies to increase the quality of air, water, etc. In 1995, Indonesia set up Indonesia's Environmental Impact Management Agency (BAPEDAL) to control pollution by evaluating and rating. A five-colour rating has been established: gold, green, blue, red and black, denoting excellent to poor, respectively (Nabiel Makarim, 1996). Companies are openly rated according to the level of pollution, which they generate. As a result, $36 \%$ of companies met the minimum standards in 1995 and 10 polluters showd a their efforts to reduce pollution (Nabiel Makarim, 1996). In Philippines, besides the 'Green policy', there is 'Brown policy' aiming at controling companies and factories, which cause pollution. Regulations are publicly announced and employees are informed about these regulations. In Laguna lake area, the authority employs "Environmental users fee system" with the issuance of 154 discharge permits. This can reduce by 2.5 million kilos ( $88 \%$ ) the BOD load to Laguna lake (Philippines Department of Environment, Brown policy, //www.denr.gov.phi). In addition, The Department of Environment and Natural Resources (DENR) of the Philippines introduced a public information program called EcoWatch in 1997, which was modelled similarly to the colour rating scheme in Indonesia (Nabiel Makarim, 1996). This aims at encouraging firms to reduce pollution and improve their colour rate so that they can have a better image to the public.

\subsection{Community involvement}

No programs or policies can be successful without the involvement of people and grass-root leaders. Apart from some severe violations, which are caused by personal interest of employees or users, most of the violation of environmental regulations is due to the ignorance or unawareness of the public. People do not understand the serious consequences of environmental degradation because they are not well informed about environmental problems and their causes. In addition, since households and industries are direct beneficiaries when environment is improved, it is required the involvement of the community. In Singapore, "green week" has been organized regularly and environmental exhibitions have been held annually, which can help people understand 
the importance of environmental conservation. This includes building environmental awareness through education at schools and public campaigns. Such programs have been launched since 1993 by Singapore Ministry of Environment. Thanks to suitable policies, Singapore can achieve urbanization and industrialization, at the same time it can still keep the quality of fresh air and clean environment (Singapore Ministry of Environment, 1997). Besides in Vietnam, "Sunday - Clean and Green" programs, which encourage volunteers to keep public places clean, are held regularly. Malaysia has also organized "Environmental Week" (MEW) since October 1997 (The Malaysia Environmental Quality Report 1997).

\subsection{Regional cooperation and support from devel- oped countries}

Developed countries have adequate facilities and suitable technologies to reduce environment deterioration. They can also get benefit when global environment is improved. In fact, in developed countries pollution is mainly prodused by the use of great amounts of fuels or other forms of gases, while in developing countries pollution is due to obsolete technology. Thus, by "the transfer of technology and know-how to developing countries and by taking the leading role in research and development to produce cheaper and cleaner abatement technologies developed countries can practically help LDCs" (Goh, 1997).

Here, the role of United Nations Development Programs and other leading countries should be highlighted. They constructed the Global Environmental Facility to deal with the conservation of environment in the 19th session of UN General Assembly on the environment, Earth Summit II. In addition, maintenance issues and proper technology in the examined context should be studied. In SEA, Singapore is leading in sharing know-how in environmental management with neighboring countries.

\section{CAUSES OF ENVIRONMENTAL PROBLEMS AND SUGGESTIONS}

Except for Singapore, other SEA countries are still struggling with environmental problems, which have emerged as crucial due to the haze in 1997 - 1998. Although new environmental policies are mandated and updated regularly, the environment has been deteriorated day by day. To explain the failure of these policies the following reasons can be stated:

\subsection{Political aspect}

Inappropriate and ineffective implementation of governmental regulations can increase the rate of a environmental deterioration. Weak law enforcement leads to inadequacy or outright corruption. The signatories or authorities fail to provide any means of law enforcement, so law violations occur often. Secondly, different levels of economic development in different areas lead to different levels of environmental consciousness of the people. Thus, the standards of resource management are hardly raised. Thirdly, political and economic influences also affect the policy-making process. Social unrest always entails serious environmental problems, such as burning, demolishing, looting or using of tear gas in Jakarta or Kuala Lumpur. Besides, some governmental officials abuse their power and indirectly contribute to the environmental degradation. In Cambodia and Thailand, the corrupted governmental officials co-operate with people who practise illegal logging. In fact, reality proves that strong law enforcement will yield a positive outcome. The Anti-pollution Unit was formed quite early in Singapore in 1970 and the Environment Ministry was set up in 1972. Many measures to protect public health and the environment have been applied.

\subsection{Socio-economic aspect}

The penetration of capitalism and the modern debt crisis lead to the clearance of many forest areas for the production of cash crops or high export-valued crops as well as to the exploitation of other natural resources, such as coal, oil, etc. The investors are eager to harvest regularly and quickly. Therefore, deforestation and dried mines are correlated with both increasing rural population and increasing debt (Mather, A.S \& Chapman, K, 1995).

The expansion of multi-national corporations and trans-national corporations should be considered. These enterprises reach Southeast Asia countries, where land and resources are still abundantly available. In most cases, they use obsolete technology in the production process, 
causing pollution and then they deny paying for their responsibility. A good example is the case of Vedan Enterprise Corporation. This company dumped over 4,500 tones of waste into the Dong Nai sea in Vietnam, which caused the death of home-raised shrimps. Although the company had to compensate with a US\$1.3 million, they fled away without paying anything (Ha Thang 7/1997).

Religion and superstition also cause people's neglect and ignorance about protecting the environment. When asked about the causes of drought and haze incidents in Brunei, over 70\% of the interviewees thought that drought was "sent as God's retribution for an erring society or community of worshipers....", while "haze was linked to two principal factors: forest fires and sin." (Odihi, 1998). Thus, people neglect the safety and fire regulations. Traditional practice can also be one of the culprits causing air pollution.

Finally, unequal distribution of income also leads to environmental damage. The governments apply pricing policy to encourage all people to save resources. However, high and middleincome people are those who use resources (electricity, water, and fuel) more, while the lowincome people have to cut down their needs due to limited budget. For instance, only the high and middle-income people can afford cars in Singapore, while the others have to rely on public transport. The same phenomenon can be seen in the housing market: private houses occupy more land than public apartments. Thus, it is noted that because wealth is distributed unequally, a small proportion of rich population consumes a large proportion of resources.

\subsection{Ecological, technical and managerial aspects}

Climate change as well as land, air and water pollution also harm the regeneration and recovering of natural resources. Global warming makes the atmosphere retain more heat from the sun. The greenhouse effect can also cause a rise in sea level and massive changes to climate and weather pattern. Ozone depletion allows more ultraviolet light through. These factors, which are mainly caused by human beings, make plants grow more slowly and entail other harms to living beings.

In case of deforestation, inappropriate technology causes damage to the residuals after logging or exploiting mines. The limited ability and skills of local staff lead to ineffective use of heavy machin- ery to exploit timber and techniques of regenerating and managing forests on a sustained-yield basis. Besides, out-of-date techniques of building sanitary systems make liquid waste overflow when it is rainy. Also, obsolete technology in the construction industry causes the waste of building materials, short-lasting housing and other problems, which violate safety regulations.

In addition, the lack of co-ordination between the governments and involved agencies can lead to ineffective management or mismanagement. The overlap of duties and regional interest hinders the implementation process. Obviously, "tragedy of common" and "common duty" are inevitable. Laws and regulations are mandated but nobody wants to implement if the implementation process will not bring direct benefit to them. For instance, in the case of forest exploitation, the cultivators do not realize the necessity to protect common-ownership property. They think that the yields are commonly used and they are not responsible to preserve for the others. This can lead to large-scale burning of forests for settlement and for agriculture to support growing population account for massive losses of forest (Mather, A.S \& Chapman, K. 1995).

From the causes mentioned above, some suggestions are presented here, which may help to minimize those shortcomings.

(i) Environmental problems usually occur in conjunction with socio-economic and political problems. Thus, a comprehensive development plan should be considered and implemented concurrently in order to achieve the goal of sustainable development. Regulatory instrument (law, regulations, decrees), economic instruments (funds for R\&D projects, education and awareness raising programs) as well as communicative instruments (media, press, exhibitions) should be combined to tackle environmental issues (Tran, 1996).

(ii) Enhancing the network for sharing knowledge and strategies, experience and lessons at both international and national levels is necessary. This will include employing of existing communicative channels to propaganda and to educate people about the cost of environmental downgrade and the benefit of environmental protection. To fulfil this task, it needs the cooperation and commitment of governments, private sector and scientific researchers and international 
institutions in the implementation. Also, drawing the attention of international agencies to get financial and technical support for specific activities and programs leading to the conservation and sustainable use of ecosystems is very crucial. A feasible option is to ask local communities to take over the responsibility as in Vietnam.

(iii) Pro-active process to develop strategic policies and measures to prevent environmental degradation should be helpful since "prevention is better than cure". Usually, the governments concentrate more on developing economic activities and human resources and somehow neglect the importance of environment in enhancing the quality of people's health and life. They wait until something happens and find the "instant solution" to solve the problem in the short-run rather than to foresee and prevent regretful events. Therefore, long-term solutions should be emphasized. Firstly, proper policies of nature reservation for both productive and protective purposes with strong legal base should become a priority. "Reduce, Regenerate, Reuse and Recycle" should be used in the propaganda campaigns for all economics sectors and the public. Secondly, multi-level governments should enhance law enforcement to reduce corruption. This requires a strong co-operation among involved agencies. Thirdly, it is important to pay more attention to technical dimension to protect natural resources more effectively. Economic development should be paralleled with environ- mental protection for the sake of sustainable development. Raising the living standards of people in rural areas can also contribute to this fight against environmental "recession".

(iv) Proper measures to punish offenders and educational sessions about environmental protection to enhance the understanding and awareness of people about their activities should be put into political agendas. Training programs should be conducted with the co-operation of grass-root and community leaders. These programs should also be expanded to rural areas where people cannot easily access information. People should understand that protecting the environment is a way to protect their own life, their health and their well-beings.

\section{CONCLUSION}

In short, sustainable development, either at micro or macro levels, is the responsibility of all human beings. The negative externalities from environment affect human life and all creatures on earth. Thus, sustainable development does not depend only on individual nations, but it is also affected by the whole world. Political, economic, environmental and cultural factors play very important roles in shaping policies to solve the environmental problems. Suitable policies and implementation, rules and evaluation criteria as well as the participation of the whole society, will contribute to the process of sustainable development.

\section{REFERENCES}

1. Do Nam (4/1997) 'Vietnam Southeast Asia Today'.

2. Environmental Report (1996) information from 'Toward Sustainable Forest Management' web site, avernor.com/english/environment.

3. Goh Siew Mui, Christina (1997) 'Environmental Policy and Natural Resource Management in Southeast Asia', Master in Public Policy Program, NUS.

4. Hamirdin B. Ithnin (1998) 'An Analysis of the 1998 Water Crisis in the Keylang Valley, Malaysia', SEAGA Conference on Teaching Geography, 30/11/1998 - 4/12-1998, Singapore.

5. John O. Odihi (1998) 'Gains in the Pains: Using the Southeast Asian 1997 - 1998 Droughts and Haze Experience for Better Environmental Management', SEAGA Conference on Teaching Geography, 30/11/1998 - 4/12/1998, Singapore.

6. Ha Thang (4/1995) 'Cities Suffocated by Mounting Trash', N. 203, Vietnam Investment Review, //202.85.89.20/viron.nsf/87bf93bc19/

7. Global Witness (9/3/1995) 'Forests, Famine and War - the Key to Cambodia's Future', http://www.oneworld.org/globalwitness/info/index.html.

8. Mather, A.S \& Chapman, K. (1995) 'The Land Resource: Forest', Environmental Resources. UK, Longman.

9. Singapore Ministry of Environment (1997) information from the exhibition of environment 6/8 - 10/8/97, World Trade Centre, Singapore.

10. Vietnam - National Plan for Environmental and Sustainable Development 1991 - 2000, by SCS, UNDP, SIDA, UNEP, IUCN, Project VIE/89/021. 
11. Hiep Nguyen Duc (1996), "Some Aspects of Air Quality in Ho Chi Minh City, Vietnam", Seminar on Environment and Development in Vietnam, December 6-7, 1996, National Centre for Development Studies, Australian National University.

12. Sheoli Pargal \& David Wheeler (2/1995), "Informal Regulation of Industrial Pollution in Developing Countries", The World Bank, Policy Research Department, Environment - Infrastructure \& Agriculture Division.

12. BAPEDAL's Nabiel Makarim talks about PROPER - Interview, "Indonesia", August 26, 1996. http://www.worldbank.int/nipr/work_paper/shakeb/23-jul-web-01.htm\#TopOfPage

13. The Malaysia Environmental Quality Report 1997, Department of Environment, http://www.jas.sains.my/doe/n_announ2a.html

14. Tran Thi Thanh Phuong (1996), "Environmental Management and Policy-Making in Vietnam", Seminar on Environment and Development in Vietnam, December 6-7, 1996, National Centre for Development Studies, Australian National University. 